\title{
PENGARUH MOTIVASI BELAJAR TERHADAP PRESTASI BELAJAR ILMU PENGETAHUAN SOSIAL SISWA SMA NEGERI WILAYAH KABUPATEN PANDEGLANG - BANTEN
}

\author{
E. Nita Prianti \\ Universitas Banten Jaya \\ Serang, Indonesia \\ Nitaprianti18@gmail.com
}

\begin{abstract}
This research was carried out aiming to pursue a goal one of which is to determine the extent of the influence of learning motivation on student achievement. With a strong motivation in students will certainly be able to increase interest and willingness in learning to guarantee the desired learning achievement in the subject of learning. the method used in this study is the correlation method which is part of the type of quantitative research. The population in this study were students of class XI of SMA Negeri Pandeglang with a total of 720 students with a total sample of 180 students taken as research data by random sampling. The results obtained there is a significant influence of learning motivation on the Social Science Learning Achievement of high school students this proves by the acquisition of Thitung = 4,372 and Sig 0,000<0.05. Learning motivation variable contributed $32.65 \%$ to the learning achievements of Social Sciences of Pandeglang Public High School students. Thus based on the results of the data obtained there is an influence of learning motivation on student achievement in SMA Negeri Pandeglang.
\end{abstract}

Keywords: Learning Motivation, Learning Achievement, Social Education Sciences, High School Students

\section{PENDAHULUAN}

Pendidikan pada dasarnya membawa pengaruh positif terhadap kelangsungan setiap individu. Pengaruh pendidikan yang dimaksud adalah proses kedewasaan seorang anak. Sekolah merupakan lembaga pendidikan formal yang tidak hanya memberikan pengetahuan pada siswa tetapi juga menambahkan nilainilai dan budi pekerti. Dalam pasal 39 Undang-Undang No. 20 tahun 2003 tentang Sistem Pendidikan Nasional, menyatakan bahwa pendidik merupakan tenaga profesional yang bertugas merencanakan dan melaksanakan proses pembelajaran, menilai hasil pembelajaran, melakukan pembimbingan dan pelatihan, serta melakukan penelitian dan pengabdian kepada masyarakat terutama bagi pendidik pada perguruan tinggi.

Secara luas, pendidikan dapat diartikan pula sebagai sebuah proses dengan metodemetode tertentu sehingga orang memperoleh pengetahuan, pemahaman, dan cara bertingkah laku yang sesuai dengan kebutuhan (Muhibin Syah : 2014). Guru adalah orang yang sangat berpengaruh dalam proses belajar mengajar. Oleh karena itu, guru betul-betul membawa siswanya 
kepada tujuan yang ingin dicapai. Profesi guru adalah pilar terpenting untuk kemajuan bangsa.

Kewajiban pendidik dan tenaga kependidikan yaitu :1) Pendidik dan tenaga pendidik berkewajiban menciptakan suasana pendidikan yang bermakna menyenangkan, kreatif, dinamis, dan dialogis; 2) Pendidik dan tenaga kependidikan berkewajiban mempunyai komitmen secara profesional untuk meningkatkan mutu pendidikan; 3) Pendidik dan tenaga kependidikan berkewajiban memberikan teladan dan menjaga nama baik lembaga, profesi, dan kedudukan sesuai dengan kepercayaan yang ditawarkan kepadanya; 4) Pendidik dan tenaga kependidikan membina keimanan dan loyalitas, pribadi terhadap ajaran islam, ideologi negara Pancasila dan Undang-Undang Dasar 1945 dan lembaga pendidik dan tenaga kependidikan berkewajiban menjungjung tinggi kebudayan bangsa sesuai dengan nilai-nilai ajaran islam; 5) Pendidik dan tenaga kependidikan berkewajiban melaksanakan tugas dengan penuh tanggung jawab dan pengabdian; 6) Pendidik dan tenaga kependidikan berkewajiban meningkatkan kemampuan profesional sesuai dengan tuntutan perkembangan ilmu pengetahuan dan teknologi; 7) Pendidik dan tenaga kependidikan berkewajiban menjaga nama baik pribadi, profesi dan lembaga sesuai dengan kepercayaan yang diberikan masyarakat, bangsa, negara dan agama.

Persoalan yang harus dikembangkan untuk mengangkat harkat martabat bangsa adalah dengan mengembangkan potensi masyarakat secara utuh dan menyeluruh (Purwanto : 2003). Dengan melalui mata pelajaran IPS di sekolah yang mempelajari tentang manusia sebagai mahluk individu yang mempunyai karakter khas masingmasing sehingga menunjukan perbedaan dengan mahluk lain. selain itu IPS mempelajari dan menunjukan bahwa manusia sebagai mahluk sosial yang selalu berkelompok dan berinteraksi dengan manusia yang lainnya dalam wadah keluarga, bangsa dan Negara.

Ilmu pengetahuan sosial adalah mata pelajaran yang focus kajiannya terhadap seperangkat peristiwa, fakta, konsep dan generalisasai yang berkaitan dengan ilmu sosial. Melalui pelajaran IPS peserta didik diarahkan untuk dapat menjadi warga Negara yang demokratis, bertanggung jawab, berpartisipasi dan menciptakan individu yang cinta damai. Melalui pembelajaran IPS yang pengertiannya disepadankan dengan belajar mengajar yang merupakan suatu proses yang sangat kompleks, karena dalam proses tersebut siswa tidak hanya sekedar menerima dan menyerap informasi yang disampaikan oleh 
guru, akan tetapi siswa dapat melibatkan diri dalam kegiatan belajar dan tindakan pedagogis yang harus dilakukan agar hasil belajar lebih baik dan sempurna. Dari proses pembelajaran tersebut siswa dapat menghasilkan suatu perubahan yang bertahap dalam dirinya.baik dalam bidang pengeahuan, keterampilan dan sikap. Adanya perubahan tersebut dapat terlihat dalam prestasi belajar yang dihasilkan oleh siswa berdasarkan evaluasi yang diberikan oleh guru.

Dalam proses belajar mengajar motivasi sangat besar peranannya terhadap prestasi belajar. karena dengan adanya motivasi dapat menumbuhkan minat belajar siswa. Sebagaimana yang di jelaskan dalam Journal oleh (Emda : 2017 : 175) bahwa motivasi adalah serangkaian usaha untuk menyediakan kondisi-kondisi tertentu, sehingga seseorang mau dan ingin melakukan sesuatu dan bila tidak suka maka akan berusaha untuk meniadakan atau mengelakkan perasaan tidak suka itu.

Selanjutnya

(Yuniarwati:2018:5)

menjelaskan bahwa motivasi adalah dorongan yang terjadi dalam diri seseorang yang dapat membangkit-kan, mengelola, mempertahankan dan menyalurkan tingkah laku agar tujuannya dapat tercapai. Bagi siswa yang memiliki motivasi yang kuat akan mempunyai keinginan untuk melaksanakan kegiatan belajar sehingga dapat mencapai suatu prestasi, yang mana prestasi itu sendiri disebut sebagai suatu keberhasilan siswa dalam belajar. Sebagaimana yang dijelaskan oleh (Sholeh \& Sa'diah : 2018 : 13) yang penulis kutip dalam jurnal pendidikan menjelaskan bahwa prestasi pembelajaran dicapai sebagai bentuk penguasaan peserta didik terhadap materi yang telah diajarkan. Prestasi belajar siswa dapat diketahui setelah diadakan evaluasi, selanjutnya hasil dari evaluasi dapat memperlihatkan tentang tinggi atau rendahnya prestasi belajar siswa ( Hamdu dan Agustina : 2011: 83) dalam (Sholeh \& Sa'diah : $2018: 13$ ).

Sehingga boleh jadi siswa yang memiliki intellegensi yang cukup tinggi menjadi gagal karena kurangnya motivasi, sebab hasil belajar akan diperoleh secara optimal bila terdapat motivasi yang tepat. Sebagaimana yang dijelaskan oleh (Djamarah : 2012 : 152) bahwa motivasi merupakan gejala psikologis dalam bentuk dorongan yang timbul pada diri seseorang sadar atau tidak sadar untuk melakukan suatu tindakan dengan tujuan tertentu. Dengan demikian maka guru dituntut untuk membangkitkan motivasi belajar dalam pembelajaran. Hal tersebut sebagaimana yang di jelaskan oleh (Sanjaya : 2010 : 261) dalam (Emda : 2017 : 179) bahwa ada beberapa hal yang harus diperhatikan oleh guru untuk membangkitkan motivasi 
belajar siswa diantaranya adalah: a) Memperjelas tujuan yang ingin dicapai; b) membangkitkan minat siswa; c) menciptakan suasana yang menyenangkan dalam belajar; d) memberikan pujian secara wajar kepada siswa e) memberikan penilaian; f) menciptakan persaingan dan kerjasama.

Dengan motivasi siswa akan belajar memahami nilai-nilai dasar yang diperlukan untuk hidup secara maksimal di masyarakat, hal tersebut pula merupakan bagian dari pelajaran IPS. Mata pelajaran IPS di sekolah sebagai salah satu mata pelajaran yang bertujuan untuk meningkatkan dan menumbuhkan pengetahuan, kesadaran, dan sikap sebagai warga Negara yang bertanggung jawab, menunut pengelolaan pembelajaran secara dinamis dengan mendekati siswa kepada realitas objektif kehidupan. Dengan pembelajaran IPS di sekolah diharapkan dapat mengembangkan berbagai kemampuan pada diri siswa, khususnya kemampuan untuk hidup di tengah-tengah lingkungan atau masyarakat tempat dimana siswa tinggal. Oleh karena itu, diperlukan tenaga guru yang mempunyai pemahaman yang memadai. Disamping itu, menguasai materi pelajaran yang menjadi tanggung jawabnya.

Motivasi sangat berperan dalam belajar, dengan motivasi inilah siswa menjadi tekun dalam kegiatan belajar mengajarnya. Dan dengan motivasi ini pula kualitas hasil belajar siswa dapat terwujud dengan baik. siswa yang dalam proses belajar mempunyai motivasi yang kuat dan jelas akan tekun dan berhasil dalam belajarnya. (Alisuf Sabri : 2001 : 82).

Selanjutnya, tingginya motivasi dalam belajar berhubungan erat dengan tingginya prestasi belajar. Bahkan hubungan antara motivasi dengan perolehan presatsi dalam belajar tidak dapat terpisahkan satu sama lain melainkan mempunyai kontribusi yang besar dari keduanya (Imron : 2002 : 89).

Dalam motivasi belajar untuk memperoleh hasil yang maksimal siswa juga perlu mendisiplinkan diri sebagai bentuk motivasi, seperti mentaati jadwal belajar dan peraturan sekolah lainnya (Sardiman : 2001: 80). Siswa yang baik adalah siswa yang tergerak hatinya untuk mengikuti aturan-aturan dan norma yang berlaku. Hal tersebut tergambar dalam mata pelajaran IPS, sehingga betapa penting dan pengaruhnya pelajaran IPS di sekolah terhadap kualitas siswa di sekolah. Adapun tujuan pengajaran Ilmu Pengetahuan Sosial (IPS) di sekolah berdasarkan standar kurikulum yang berbasis kompetensi agar peserta didik memiliki kemampuan sebagai berikut: 1) Memahami konsep-konsep yang berkaitan dengan kehidupan masyarakat dan lingkungannya; 2) Berfikir logis dan 
kritis, rasa ingin tahu, memecahkan masalah dan terampil dalam kehidupan sosial; 3) Berkomitmen terhadap nlai-nilai sosial dan kemanusiaan; 4) Berkomunikasi, bekerjasama, dan berkompetensi dalam masyarakat yang majemuk di tingkat local, nasional, dan global.

Oleh karena itu, dalam mempelajari ilmu pengetahuan sosial, siswa diharapkan dapat berfikir secara logis dan kritis, mampu memecahkan masalah dan terampil dalam kehidupan sosial. Pelajaran Ilmu Pengetahuan Sosial di sekolah dapat membangkitkan kesadaran siswa dalam hidup bermasyarakat, sehingga tumbuh adanya kesadaran kebersamaan dalam kehidupan sosial. Namun, berdasarkan fenomena yang ada di sekolah - sekolah mata pelajaran IPS merupakan salah satu pelajaran yang dianggap sebagai mata mata pelajaran yang menjenuhkan. Hal ini disebabkan oleh kajian materi yang cukup luas dan materi yang terdapat di dalamnya dalam bentuk materi hafalan. Selain itu, kajian materi dalam pelajaran IPS sebagian besar guru menyampaikan dalam bentuk ceramah, bahkan siswa tidak jarang ketika pada saat belajar tidak dilibatkan untuk berperan aktif di kelas. Sehingga tidak jarang pelajaran IPS dianggap dinomorduakan dibandingkan dengan pelajaran yang lain.
Ketidaktertarikan siswa terhadap pelajaran IPS karena motivasi belajar yang dianggap masih rendah, sehingga sangat berpengaruh terhadap hasil perolehan prestasi belajarnya. Oleh karena itu, tentu sebagai seorang guru harus terus berusaha untuk menarik perhatian anak didiknya sehingga mereka mempunyai minat untuk memotivasi diri terhadap pelajaran yang diajarkannya.

\section{METODE PENELITIAN}

Penelitian ini dilaksanakan pada siswa siswi kelas XI SMA Negeri Wilayah Kabupaten Pandeglang. peneliti menggunakan metode survey dengan analisis korelasi ganda yang merupakan bagian dari jenis penelitian kuantitatif. Penelitian yang digunakan adalah penelitian analisis deskriptif yaitu suatu metode penelitian yang mengambil sampel dari suatu populasi dan menggunakan kuisioner sebagai alat pengumpul data. Menurut (Suharsimi Arikunto : 2010 : 108) populasi adalah keseluruhan objek penelitian. Selanjutnya masih dalam Suharsimi Arikunto apabila subjeknya kurang dari 100, diambil semua sekaligus sehingga penelitannya adalah penelitian populasi. Jika jumlah subjeknya besar, maka diambil $10-15 \%$ atau $20-25 \%$ atau lebih. Berdasarkan penjelasan si atas maka populasi dalam penelitian ini adalah 
siswa siswi kelas XI SMA Negeri Pandeglang yang berjumlah 720 siswa. Dengan demikian maka peneliti akan menentukan jumlah sampel dalam penelitian berdasarkan pendapat Arikunto yaitu diambil sebanyak $25 \%$ untuk dijadikan sebagai sampel. Oleh karena itu, berdasarkan perhitungan yang telah dilakukan oleh peneliti adalah sebanyak 180 siswa yang diambil secara random sampling.

Metode pengumpulan data yang digunakan dalam penelitian ini yaitu dengan angket/kuisioner dengan tujuan agar mempermudah dalam melakukan penelitian di lapangan. Sehingga dapat memberikan gambaran yang kongkrit dalam penelitian tersebut. Adapun teknik pengambilan data yang digunakan dalam penelitian ini adalah sebagai berikut:

a) Memperoleh data mengenai prestasi belajar IPS dengan mengambil dari dokumen guru berupa nilai raport (dokumentasi)

b) Teknik pengambilan data motivasi dilakukan dengan cara menyebar angket dan kuisioner kepada siswa yang menjadi sampel.

c) Secara oprasional motivasi belajar siswa merupakan skor hasil pengukuran tentang

kemauan belajar siswa melalui indicator sebagai berikut:
Tabel 1. Kisi-kisi Instrumen Motivasi Belajar

\begin{tabular}{|c|c|c|c|}
\hline No & Indikator & $\begin{array}{l}\text { Nomor Butir } \\
\text { Soal }\end{array}$ & $\begin{array}{c}\text { Jumlah } \\
\text { soal }\end{array}$ \\
\hline 1. & Disiplin belajar & $1,2,3,4,5$ & 5 \\
\hline 2. & $\begin{array}{l}\text { Dorongan } \\
\text { untuk } \\
\text { berprestasi }\end{array}$ & $6,7,8,9,10$ & 5 \\
\hline 3. & Rasa ingin tahu & $\begin{array}{c}11,12,13,14 \\
15\end{array}$ & 5 \\
\hline 4. & $\begin{array}{l}\text { Kesiapan } \\
\text { menghadapi }\end{array}$ & $\begin{array}{c}16,17,18,19 \\
20\end{array}$ & 5 \\
\hline 5. & $\begin{array}{l}\text { Kesulitan } \\
\text { Minat Belajar } \\
\text { UMLAH }\end{array}$ & $\begin{array}{c}21,22,23,24 \\
25\end{array}$ & $\begin{array}{c}5 \\
25\end{array}$ \\
\hline
\end{tabular}

Kalibrasi Instrumen variabel motivasi belajar

\section{Uji Validitas}

Untuk mengukur uji validitas dilakukan dengan cara mengkorelasikan setiap butir alat ukur dengan skor total yang merupakan jumlah tiap skor tiap butir dengan menggunakan rumus Person Produck Moment 


$$
\text { Rumus : } \mathrm{r}_{\mathrm{xy}}=\frac{N \sum X Y-\left(\sum X\right)\left(\sum Y\right)}{\sqrt{\left\{N \sum X^{2}-\left(\sum X^{2}\right)\right\}\left\{N \sum Y^{2}-\left(\sum Y^{2}\right)\right\}}}
$$

Keterangan :

$$
\begin{array}{lll}
\mathrm{r}_{\mathrm{xy}} & = & \text { Koefisien korelasi product moment } \\
\Sigma \mathrm{X} & = & \text { Jumlah skor dalam sebaran } \mathrm{X} \\
\Sigma \mathrm{Y} & = & \text { Jumlah skor dalam sebaran } \mathrm{Y} \\
\Sigma \mathrm{X}^{2} & = & \text { Jumlah skor yang dikuadratkan dalam sebaran } \mathrm{X} \\
\Sigma \mathrm{Y}^{2} & = & \text { Jumlah skor yang dikuadratkan dalam sebaran } \mathrm{Y} \\
\mathrm{N} & = & \text { Banyaknya responden }
\end{array}
$$

\section{Uji Reliabilitas}

Untuk mengukur reliabilitas maka peneliti mengguakan rumus Alpha Cronbach dengan rumus sebagai berikut:

$$
r_{11}=\left(\frac{n}{n-1}\right)\left(1-\frac{\sum \sigma_{i}^{2}}{\sigma_{t}^{2}}\right)
$$

Berdasarkan hasil perhitungan diperoleh hasil bahwa dari 25 butir instrument pernyataan motivasi belajar yang diujicobakan 7 butir pernyataan dinyatakan tidak valid yaitu No. 3, 6, 10, 15, 18, 19 dan 25 sehingga instrument yang dipakai untuk sampel sebanyak 18 butir pernyataan dengan tingkat reliabilitas 0.942 .

\section{Teknik Analisis Data}

Teknik analisis statistic adalah pengujian data hasil penelitian yang dilakukan dengan menyajikan data dalam bentuk perhitungan statistic dasar yang meliputi tabel distribusi frekuwensi , histogram, nilai rata-rata, median, modus, simpangan baku, dengan rumus sebagai berikut:
a. Rata - Rata $=\frac{\sum X}{N}$
Keterangan : $\quad \mathrm{x}=$ rata-rata 
$\mathrm{x}=$ jumlah tiap data

$\mathrm{n}=$ jumlah data

b. Median $=M e=1 / 2(n+1)$ dimana $n=$ jumlah data

c. Modus $=b+$

Keterangan: $\quad\left(b_{1}+b_{2}\right)$

Mo $=$ nilai modus

$\mathrm{b}=$ batas bawah nilai yang mengandung nilai modus

$\mathrm{P}=$ panjang kelas nilai modus

$\mathrm{b}_{1}=$ selisih antara frekwensi modus dengan frekwensi sebelumnya

$\mathrm{b}_{2}=$ selisih antara frekwensi modus dengan frekwensi sesudahnya.

d. Simpangan baku

$$
\sqrt{\frac{{ }_{n} \Sigma x_{2}-(\Sigma x)_{2}}{n(n-1)}} \text { atau } \quad \mathrm{s}=\sqrt{\frac{\sum x^{2}}{n-1}}
$$

Proses perhitungan dilakukan dengan bantuan program SPSS Ver.20.0 dan Microsoft Excel 2010.

\section{Hipotesis Statistik}

$\mathrm{H}_{0}: \beta_{1}=0$

$\mathrm{H}_{1}: \beta_{1} \neq 0$

Keterangan :

$\mathrm{H}_{0}=$ Tidak terdapat pengaruh motivasi belajar siswa terhadap prestasi belajar siswa pada pelajaran IPS.

$\mathrm{H}_{1}=$ Terdapat pengaruh motivasi belajar siswa terhadap prestasi belajar pada pelajaran IPS

Dari rumusan di atas maka penulis mengemukakan rancangan pengaduan hipotesis berikut:

1. Jika $\mathrm{t}_{\text {-hitung }} \leq \mathrm{t}_{\text {-tabel }}$ maka $\mathrm{H}_{\mathrm{o}}$ dapat diterima dan Ha ditolak. Dengan demikian bahwa antara variabel $\mathrm{X}$ dan $\mathrm{Y}$ tidak terdapat pengaruh yang signifikan. 
2. Jika t-hitung $\geq \mathrm{t}_{\text {-tabel }}$ maka $\mathrm{H}_{\mathrm{o}}$ ditolak dan Ha diterima. Dengan demikian bahwa antara variabel $\mathrm{X}$ dan $\mathrm{Y}$ terdapat pengaruh yang berarti signifikan.

\section{HASIL PENELITIAN DAN PEMBAHASAN}

\section{Deskripsi Data}

\section{Data Motivasi Belajar (X)}

Data motivasi belajar yang diperoleh dari kuisioner yang di jawab oleh 180 siswa dihasilkan skor terendah 20, skor tertinggi 97, skor rerata sebesar 60.97, median 63, modus sebesar 64 dan simpangan bakunya adalah sebesar 17.176.

\section{Tabel 2. Deskripsi Data Penelitian Motivasi Belajar Siswa}

\begin{tabular}{lrr}
\multicolumn{2}{c}{} & \multicolumn{2}{c}{ Statistics } \\
Motivasi & Belajar \\
$\mathrm{N}$ & Valid & 180 \\
& Missing & 0 \\
Mean & 60,97 \\
Median & 63,00 \\
Mode & 64 \\
Std. Deviation & 17,176 \\
Minimum & 20 \\
Maximum & 97 \\
\hline
\end{tabular}

Dari hasil perhitungan di atas, maka bisa dikatakan bahwa Minat Belajar Siswa-siswi SMA Negeri di wilayah Pandeglang cukup baik. Hal ini di indikasikan dengan perolehan skor rerata sebesar 60,97. Untuk memperjelas data di atas dapat digambarkan dalam histogram sebagai berikut:

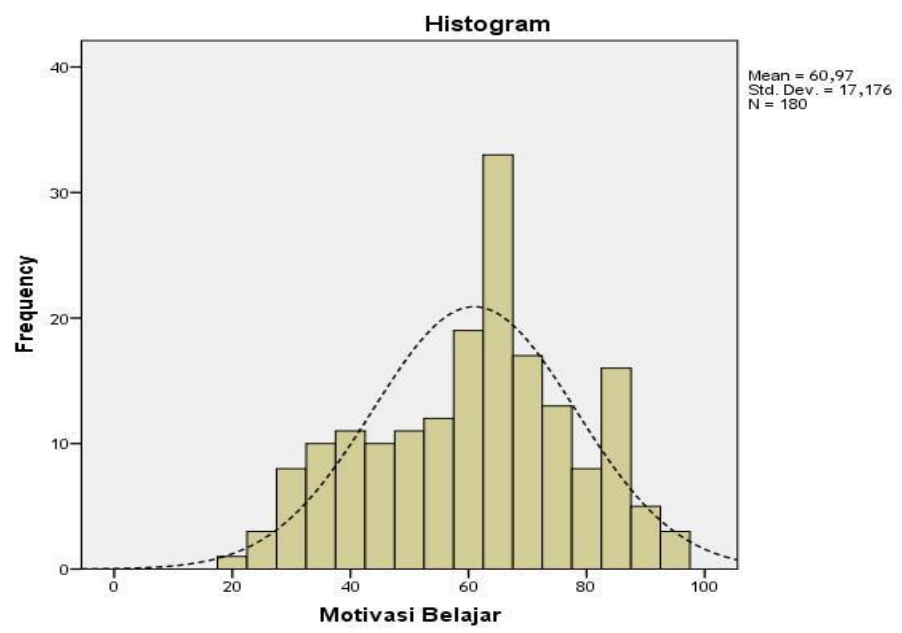

Gambar 1. Histogram Poligon Variabel Motivasi Belajar 
Dari histogram dan polygon frekuensi di atas dapat disimpulkan bahwa motivasi belajar SMA Negeri di wilayah Pandeglang memiliki sebaran yang cukup normal.

\section{Data Prestasi Belajar Ilmu Pendidikan Sosial (IPS-Y)}

Data prestasi belajar IPS diperoleh dari nilai raport. Responden yang menjadi sampel penelitian sebanyak 180 siswa. Skor yang diperoleh adalah terendah 25, skor tertinggi 100, skor rerata sebesar 66.22 median sebesar 65 , modus sebesar 70 dan simpangan baku sebesar 17.106

Tabel. 3. Deskripsi data penelitian prestasi belajar IPS

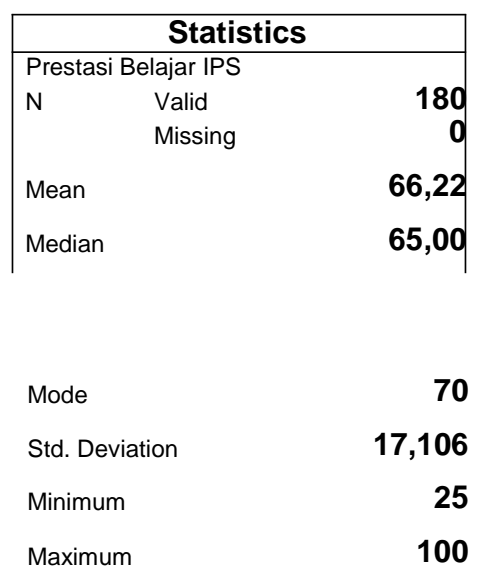

Bila dilihat dari hasil perhitungan di atas, maka bisa dikatakan bahwa prestasi belajar IPS siswa SMA Negeri Pandeglang tergolong baik. Hal ini di indikasikan dengan perolehan nilai rata-rata sebesar 66,22.Untuk memperjelas data di atas, digambarkan dalam histogram sebagai berikut :

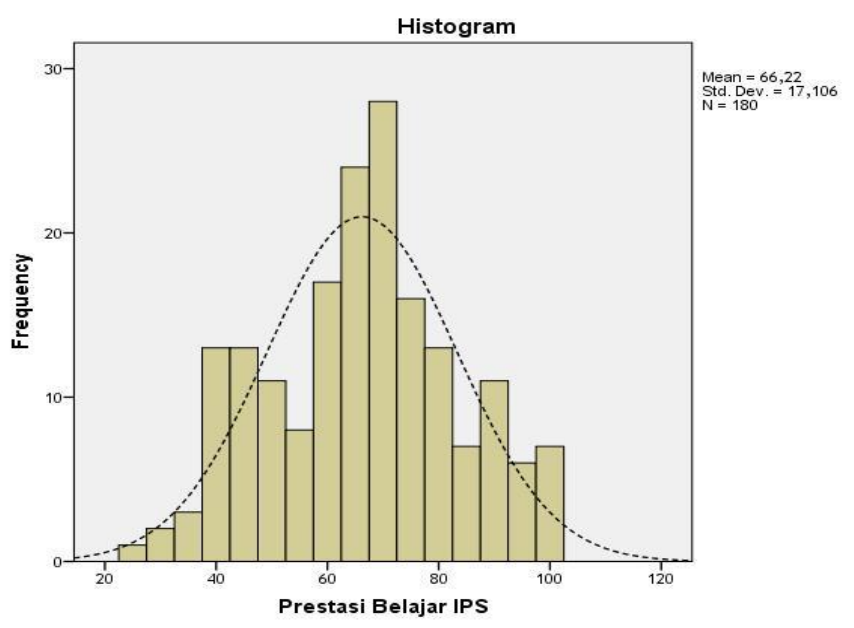




\section{Gambar. 2. Histogram Poligon Variabel Prestasi Belajar IPS}

Dari histogram dan polygon frekuensi di atas dapat disimpulkan bahwa prestasi Belajar IPS

SMA Negeri Pandeglang memiliki sebaran yang normal.

\section{Uji Normalitas}

Tabel 4. Uji Normalitas

\begin{tabular}{|c|c|c|c|c|}
\hline \multicolumn{5}{|c|}{ One-Sample Kolmogorov-Smirnov Test } \\
\hline & & \begin{tabular}{|l|} 
Prestasi Belajar \\
IPS
\end{tabular} & Motivasi Belajar & $\begin{array}{l}\text { Persepsi Siswa atas } \\
\text { Lingkungan Sekolah }\end{array}$ \\
\hline \multicolumn{2}{|l|}{$\bar{N}$} & 180 & 180 & 180 \\
\hline \multirow{2}{*}{$\begin{array}{l}\text { Normal } \\
\text { Parameters }\end{array}$} & Mean & 66,22 & 60,97 & 57,81 \\
\hline & Std. Deviation & 17,106 & 17,176 & 17,031 \\
\hline \multirow{3}{*}{$\begin{array}{l}\text { Most Extreme } \\
\text { Differences }\end{array}$} & Absolute &, 094 & ,085 & ,092 \\
\hline & Positive & ,079 & ,050 & ,074 \\
\hline & Negative &,- 094 &,- 085 &,- 092 \\
\hline \multicolumn{2}{|c|}{ Kolmogorov-Smirnov Z } & 1,258 & 1,142 & 1,235 \\
\hline \multicolumn{2}{|c|}{ Asymp. Sig. (2-tailed) } &, 085 & ,147 & ,095 \\
\hline \multicolumn{5}{|c|}{ a. Test distribution is Normal. } \\
\hline
\end{tabular}

Dari table di atas menunjukkan bahwa kedua variable yang menyatakan distribusi pada analisis regresi ini mengikuti distribusi normal. Hal ini ditunjukkan dengan nilai Sig. untuk semua variabel $>0,05$. Hal ini berarti asumsi atau persyaratan analisis regresi terpenuhi.

\section{Uji Linearitas}

Uji linearitas dilakukan untuk menentukan teknik dalam analisis regresi apakah variabel bebas $\mathrm{X}$ dan Variabel terikat $\mathrm{Y}$ terbentuk secara linear. Hasil uji linearitas regresi antara motivasi belajar dengan prestasi Belajar IPS, perhitungan SPSS 20.0 sebagai berikut:

Tabel 5. Hasil Pengujian Linearitas Regresi Variabel $Y$ atas $X_{1}$

\begin{tabular}{|c|c|c|c|c|c|c|c|}
\hline \multicolumn{8}{|c|}{ ANOVA Table } \\
\hline & & & Sum of Squares & $d f$ & Mean Square & $\bar{F}$ & Sig. \\
\hline \multirow{5}{*}{$\begin{array}{l}\text { Prestasi Belajar } \\
\text { IPS * Motivasi } \\
\text { Belajar }\end{array}$} & \multirow{3}{*}{$\begin{array}{l}\text { Between } \\
\text { Groups }\end{array}$} & (Combined) & 39425,040 & 63 & 625,794 & 5,603 &, 000 \\
\hline & & Linearity & 31057,838 & 1 & 31057,838 & 278,071 &, 000 \\
\hline & & $\begin{array}{l}\text { Deviation } \\
\text { from Linearity }\end{array}$ & 8367,201 & 62 & 134,955 & 1,208 & 190 \\
\hline & \multicolumn{2}{|c|}{ Within Groups } & 12956,071 & 116 & 111,690 & & \\
\hline & \multicolumn{2}{|l|}{ Total } & 52381,111 & 179 & & & \\
\hline
\end{tabular}


Berdasarkan hasil perhitungan di atas diperoleh hasil perhitungan Deviation from Linearity dengan Fo $=1,208$ dan Sig. $=0,190>0,05$. Hal ini memiliki pengertian bahwa variabel motivasi belajar dengan prestasi Belajar IPS siswa mempunyai mempunyai hubungan yang linear. Dapat disimpulkan bahwa terdapat pengaruh antara motivasi belajar $(\mathrm{X})$ terhadap prestasi belajar IPS siswa SMA Negeri Wilayah Kabupaten Pandeglang (Y). Apabila dengan cara membandingkan jika $\mathrm{F}_{\text {hitung }} \leq \mathrm{F}_{\text {tabel }}$ maka terdapat hubungan yang linier antara variabel $\mathrm{X}$ dengan Variabel $Y$. Sebaliknya jika $F_{\text {hitung }} \geq F_{\text {tabel }}$ maka tidak terdapat hubungan yang linier antara kedua variabel tersebut. Berdarkan tabel hasil perhitungan SPPS. 20 di atas menunjukan linieritas, yaitu dengan pembuktian hasil perolehan $F_{\text {hitung }}=1,208$ sedang $F_{\text {tabel }}$ 1.43. Data yang diperoleh tersebut artinya $F_{\text {hitung }} \leq F_{\text {tabel }}$ yaitu $1,208 \leq 1.43$ Artinya data perolehan tersebut menunjukan linieritas antara variabel X dengan Variabel Y.

\section{Hipotesis yang diuji:}

Tabel 6. Hasil Perhitungan Persamaan Regresi Ganda Variabel X terhadap Y

\begin{tabular}{|c|c|c|c|c|c|c|}
\hline \multicolumn{7}{|c|}{ Coefficients $^{\mathrm{a}}$} \\
\hline \multicolumn{2}{|c|}{ Model } & \multicolumn{2}{|c|}{ Unstandardized Coefficients } & \multirow{2}{*}{\begin{tabular}{|l|}
$\begin{array}{l}\text { Standardized } \\
\text { Coefficients }\end{array}$ \\
Beta
\end{tabular}} & \multirow[t]{2}{*}{$T$} & \multirow[t]{2}{*}{ Sig. } \\
\hline & & $\mathrm{B}$ & Std. Error & & & \\
\hline \multirow[t]{3}{*}{1} & (Constant) & 17,674 & 2,927 & & 6,038 &, 000 \\
\hline & Motivasi Belajar & ,422 & ,097 & ,424 & 4,372 & ,000 \\
\hline & & ,394 & ,097 & ,393 & 4,049 &, 000 \\
\hline
\end{tabular}

Pengaruh Motivasi Belajar (X) terhadap Prestasi Belajar IPS (Y)

Hipotesis yang diuji:

Artinya:

$\mathrm{H}_{0}$ : tidak terdapat pengaruh motivasi belajar terhadap prestasi Belajar IPS

$\mathrm{H}_{1}$ : terdapat pengaruh motivasi belajar terhadap prestasi Belajar IPS

Dari table di atas dapat dinyatakan bahwa terdapat pengaruh motivasi belajar terhadap prestasi Belajar IPS secara signifikan. Tabel koefisien di atas menunjukan 
bahwa nilai constant sebesar 17.674 sedangkan nilai X (Motivasi) koefisien regresi sebesar 0.422 hal tersebut diartikan bahwa koefisien regresi tersebut bernilai positif, sehingga dapat dikatakan bahwa pengaruh antara variabel $\mathrm{X}$ terhadap $\mathrm{Y}$ bernilai positif atau memiliki signifikansi. Selanjutnya berdasarkan pembuktian nilai t hitung Hal ini dibuktikan dengan perolehan nilai thitung $=4,372$ dan Sig. $0,000<0,05$. Dari tabel statistic juga dapat menjelaskan bahwa variable motivasi belajar memberikan kontribusi sebesar 32,65 \% terhadap peningkatan prestasi Belajar IPS.

\section{KESIMPULAN}

Berdasarkan hasil analisa data yang telah diuraikan di atas, maka dapat diambil kesimpulan sebagai berikut:

Terdapat pengaruh motivasi belajar terhadap prestasi Belajar IPS secara signifikan. Hal ini dibuktikan dengan perolehan nilai $t_{\text {hitung }}=4,372$ dan Sig. $0,000<0,05$. Variable motivasi belajar memberikan kontribusi sebesar 32,65 \% terhadap peningkatan prestasi Belajar IPS.

\section{DAFTAR PUSTAKA}

\section{Buku}

Alisuf Sabri. 2001. Pengantar Psikologi Umum dan Perkembangan. Jakarta. Ilmu Jaya

Arikunto, Suharsimi. 2010. Prosedur Penelitian. Jakarta. Rineka Cipta
Djamarah. 2012. Psikologi Belajar. Jakarta. Rineka Cipta

Imron, Ali. 2002. Belajar dan Pembelajaran. Jakarta. Pustaka Jaya

Purwanto. 2003. Psikologi Pendidikan. Bandung. PT. Remaja Rosdakarya

Sardiman, A. M. 2001. Interaksi dan Motivasi Belajar Mengajar. Jakarta. Raja Grafindo

Syah, Muhibin. 2014. Psikologi Pendidikan. Bandung: PT. Remaja Rosdakarta Offset.

\section{Jurnal:}

Emda, Amna. 2017. Kedudukan Motivasi Belajar Siswa dalam Pembelajaran. Lantanida Journal. Vol 5 No. 2. Hal: 172-182. Di akses pada tanggal 1808-2020 dari: https://jurnal.arraniry.ac.id/index.php/ lantanida/article/view/2838/2064

Yiniarwati. 2018. Meningkatkan Motivasi Belajar Melalui Layanan Bimbingan Kelompok Dengan Teknik Modeling Pada Siswa Kelas XI APH 1 SMK N I Cepu Semester Gasal Tahun 2017 / 2018. Empati Jurnal Bimbingan dan Konseling . Vol. 5 No. 1. Hal:1-11. 
Di akses pada tanggal 18-08-2020

dari:

http://103.98.176.9/index.php/EMPA

TI/article/viewFile/2926/2102

Sholeh, Badrus \& Sa'diah. 2018. Pengaruh

Motivasi Belajar Dan Fasilitas

Belajar Terhadap Prestasi Belajar

Ips Siswa Smp Nurul Iman Parung

Bogor Tahun Ajaran 2017/2018.

PEKOBIS (Jurnal Pendidikan,

Ekonomi dan Bisnis). Vol.3 No. 2.

Hal:12-20. Di akses pada tanggal 18-

08-2020 dari:

http://www.openjournal.unpam.ac.id/

index.php/Pekobis/article/view/2041/

$\underline{1697}$ 